\title{
Ischemic preconditioning induces autophagy and limits necrosis in human recipients of fatty liver grafts, decreasing the incidence of rejection episodes
}

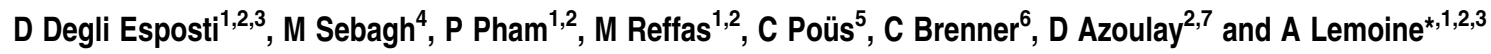

Whether ischemic preconditioning (IP) reduces ischemia/reperfusion (I/R) injury in human normal and fatty livers remains controversial. We compared two independent groups of liver donor transplants with versus without steatosis to evaluate IP consequences. Liver donors with $(n=22)$ or without $(n=28)$ steatosis either did or did not undergo IP before graft retrieval. Clinical data from the recipients, as well as histological and immunohistological characteristics of post-reperfusion biopsies were analyzed. Incidence of post-reperfusion necrosis was increased (10/10 versus $9 / 14$, respectively; $P<0.05)$ and the clinical outcome of recipients was worse for non-IP steatotic liver grafts compared with non-IP non-steatotic grafts. IP significantly lowered the transaminase values only in patients receiving a non-steatotic liver. An increased expression of beclin-1 and LC3, two pro-autophagic proteins, tended to decrease the incidence of necrosis $(P=\mathbf{0 . 0 6 7})$ in IP steatotic livers compared with non-IP steatotic group. IP decreased the incidence of acute and chronic rejection episodes in steatotic livers $(2 / 12$ versus $6 / 10 ; P=0.07$ and $2 / 12$ versus $7 / 10 ; P<0.05$, respectively), but not in non-steatotic livers. Thus, IP may induce autophagy in human steatotic liver grafts and reduce rejection in their recipients.

Cell Death and Disease (2011) 2, e111; doi:10.1038/cddis.2010.89; published online 13 January 2011

Subject Category: Experimental Medicine

In steatotic livers, hepatocytes cell death and inflammatory response have a great impact in both surgical and medical context. $^{1,2}$ Indeed, steatotic livers are more sensitive to ischemiareperfusion (I/R) injury. ${ }^{3,4}$ Operative mortality rate associated with steatosis after major liver resection has been reported as high as $14 \%$ compared with $2 \%$ for healthy livers. ${ }^{4}$ Steatotic liver grafts are more frequently used in the context of transplantation and they are associated with a primary non-function rate of $60 \%$ compared with $<5 \%$ for non-steatotic grafts. ${ }^{5,6}$ Therefore, developing protective strategies to minimize the adverse effects of $\mathrm{I} / \mathrm{R}$ injury in steatotic livers is of paramount importance.

Ischemic preconditioning (IP), first described in the heart by Murry et al., ${ }^{7}$ consists of brief periods of vascular occlusion which confer protection against subsequent I/R via endogenous protective mechanisms. In the liver, IP was shown to lower transaminase levels and reduce endothelial cell injury. ${ }^{8}$ This protection has been linked to various mechanisms, such as decreased apoptosis, ${ }^{9}$ preservation of the ATP content in liver tissue, ${ }^{8,10}$ or overproduction of pro-survival and antiinflammatory proteins. ${ }^{11}$

The beneficial effects of IP in human liver hepatectomy, associated with warm and short ischemia have been demonstrated in young patients and patients with liver steatosis. ${ }^{8}$ In liver transplantation, some previous studies have demonstrated controversial results of the role of IP on liver grafts. Our group was the first to show a significant decrease in transaminase levels after IP counterbalanced by decreased early function of the graft. ${ }^{12}$ Jassem et al. ${ }^{13}$ found a significant reduction of transaminase levels in IP patients compared with non-IP patients in the post-operative period, whereas Koneru et al., ${ }^{14}$ found a paradoxal effect of higher transaminase peak in IP livers. These studies have shown that steatosis was a significant worsening parameter for $\mathrm{I} / \mathrm{R}$ injuries, although none of them have specifically studied the role of IP on steatotic or non-steatotic livers. Recently, Franchello et al. ${ }^{15}$ compared normal livers with marginal livers, including mostly livers from donors over the age of 60 . They have shown that IP reduced the AST and ALT mean levels $5 \mathrm{~min}$ after reperfusion during the first 3 operative days. Interestingly, they also observed that IP induced a lower rate of hepatocyte cell death as assessed by TUNEL assay, the apoptotic index being higher in marginal livers compared with normal livers outside the context of preconditioning. Therefore, our objective was to focus on macro-microvesicular

\footnotetext{
${ }^{1}$ AP-HP, Hôpital Paul Brousse, Service de Biochimie et Biologie Moléculaire, 14 Avenue Paul Vaillant Couturier, Villejuif Cedex 94804, France; ${ }^{2}$ Inserm U1004, Université Paris 11, Institut André Lwoff, PRES Universud-Paris, 12-14 Avenue Paul Vaillant Couturier, Villejuif 94800, France; ${ }^{3}$ Faculté de Pharmacie, 5 rue Jean Baptiste Clément, Châtenay-Malabry Cedex 92296, France; ${ }^{4}$ AP-HP, Hôpital Paul Brousse, Service d'Anatomie Pathologique, Inserm U785, Université Paris 11, Institut André Lwoff, 14 Avenue Paul Vaillant Couturier, Villejuif Cedex 94804, France; ${ }^{5} E A 4530$, Laboratoire de Biochimie et Biologie Cellulaire, Faculté de Pharmacie, 5 rue Jean Baptiste Clément, Châtenay-Malabry Cedex 92296, France; ${ }^{6}$ UMR-S 769 Signalisation et Physiopathologie Cardiaque, Université Paris 11, PRES Universud-Paris, Faculté de Pharmacie, 5 rue Jean Baptiste Clément, Châtenay-Malabry Cedex 92296, France and ${ }^{7}$ AP-HP, Hôpital Paul Brousse, Centre Hépatobiliaire, 14 Avenue Paul Vaillant Couturier, Villejuif Cedex 94804, France

${ }^{*}$ Corresponding author: A Lemoine, AP-HP, Hôpital Paul Brousse, Service de Biochimie et Biologie Moléculaire, 14 Avenue Paul Vaillant Couturier, Villejuif 94800 , France. Tel: + 33014559 3693; Fax: + 33014559 3625; E-mail: antoinette.lemoine@pbr.aphp.fr, antoinette.lemoine@ u-psud.fr Keywords: steatosis; liver transplantation; ischemia/reperfusion; ischemic preconditioning; autophagy; liver Abbreviation: IP, ischemic preconditioning
}

Received 04.10.10; revised 10.11.10; accepted 18.11.10; Edited by M Federici 
steatotic livers that underwent cold ischemia, and preservation during liver transplantation to determine whether and how IP could influence cell death and clinical efficacy or safety in the recipients.

\section{Results}

Donor, recipient and intraoperative data. In all, 22 donor livers out of 50 showed steatosis. Steatosis was globally graded as mild ( $<30 \%$ of steatotic hepatocytes) in 16 livers and moderate in 6 (steatotic hepatocytes $>30 \%$ but $<60 \%$ ). In all, 17 livers showed mixed macro and microvesicular steatosis, with macrovesicular ranging from $>1$ to $\leq 30 \%$ and microvesicular ranging from $>5$ to $\leq 50 \%$. Three steatotic liver grafts showed only microvesicular steatosis ranging from 20 to $40 \%$ of hepatocytes. Two others showed only macrovesicular steatosis affecting $10 \%$ of hepatocytes. There was no significant difference in distribution of age and hospitalization stay for graft donors before transplantation between groups (Table 1). No significant differences were observed in recipients with regard to age, gender or initial disease before transplantation (Table 2), nor for surgical parameters (Table 3).

Clinical and histological outcomes in patients receiving non-steatotic or steatotic allografts without IP. When comparing the two groups of patients who did not undergo IP, higher mean values in both peak and day 5 levels of AST and ALT were observed in recipients of steatotic grafts compared with recipients of non-steatotic grafts, although these differences were not statistically significant because of high inter-patient variability (Table 4). Mean AST and ALT peaks were 862 and $728 \mathrm{IU} / \mathrm{I}$ in patients receiving steatotic grafts, whereas they were 458 and $577 \mathrm{IU} / \mathrm{l}$ in patients receiving non-steatotic grafts. AST and ALT day 5 levels were 139 and $423 \mathrm{IU} / \mathrm{l}$ in patients receiving steatotic grafts and 79 and $247 \mathrm{IU} / \mathrm{I}$ in patients receiving non-steatotic grafts (Table 4). Levels of serum bilirubin at day 7 were significantly higher in steatotic livers compared with non-steatotic livers, whereas no difference was observed in PT levels (Table 4). No significant differences in post-transplantation intensive care unit stay (12 days versus 11 days) or total hospitalization stay

Table 1 Allografts characteristics before transplantation in IP and non-IP donors

\begin{tabular}{|c|c|c|c|c|c|c|c|c|}
\hline \multirow[b]{2}{*}{ Variable } & \multicolumn{2}{|c|}{ Non-steatotic allografts } & \multicolumn{2}{|c|}{ Steatosic allografts } & \multirow[b]{2}{*}{$\begin{array}{l}\text { P-value } \\
\text { I versus } \text { II }^{\mathrm{a}}\end{array}$} & \multirow[b]{2}{*}{$\begin{array}{l}\text { P-value } \\
\text { III versus IV }\end{array}$} & \multirow[b]{2}{*}{$\begin{array}{c}\text { P-value } \\
\text { I versus III }\end{array}$} & \multirow[b]{2}{*}{$\begin{array}{l}\text { P-value } \\
\text { II versus IV }\end{array}$} \\
\hline & $\begin{array}{l}\text { IP }(n=14) \\
\text { group I }\end{array}$ & $\begin{array}{l}\text { Non-IP }(n=14) \\
\text { group II }\end{array}$ & $\begin{array}{l}\text { IP }(n=12) \\
\text { group III }\end{array}$ & $\begin{array}{l}\text { Non-IP }(n=10) \\
\text { group IV }\end{array}$ & & & & \\
\hline Age of donor (years) & $47.9 \pm 13.6$ & $50.1 \pm 12.1$ & $50.5 \pm 8.4$ & $54.7 \pm 10.3$ & 0.65 & 0.30 & 0.57 & 0.34 \\
\hline $\begin{array}{l}\text { Donor hospitalization } \\
\text { (days in intensive care unit) }\end{array}$ & $1.9 \pm 1.1$ & $1.8 \pm 1.0$ & $2.1 \pm 1.3$ & $1.6 \pm 0.9$ & 0.67 & 0.38 & 0.73 & 0.77 \\
\hline Body mass index & $21.7 \pm 3.3$ & $23.7 \pm 2.9$ & $25.1 \pm 3.7$ & $24.9 \pm 2.3$ & 0.11 & 0.87 & 0.02 & 0.29 \\
\hline \multicolumn{9}{|l|}{ Histology before reperfusion } \\
\hline Absent & $12 / 14$ & $13 / 14$ & $12 / 12$ & $9 / 10$ & 0.39 & 0.45 & 0.28 & 0.51 \\
\hline Mild & $1 / 14$ & $1 / 14$ & $0 / 12$ & $0 / 10$ & 0.52 & - & 0.54 & 0.58 \\
\hline Moderate & $1 / 14$ & $0 / 14$ & $0 / 12$ & $1 / 10$ & 0.50 & 0.45 & 0.54 & 0.42 \\
\hline \multicolumn{9}{|l|}{ Steatosis } \\
\hline Absent & $14 / 14$ & $14 / 14$ & $0 / 12$ & $0 / 10$ & - & - & $10^{-7}$ & $5 \times 10^{-7}$ \\
\hline Mild (0-30\%) & $0 / 14$ & $0 / 14$ & $8 / 12$ & $8 / 10$ & - & 0.30 & $3 \times 10^{-4}$ & $6 \times 10^{-5}$ \\
\hline Moderate (30-60\%) & $0 / 14$ & $0 / 14$ & $4 / 12$ & $2 / 10$ & - & 0.30 & 0.03 & 0.16 \\
\hline $\begin{array}{l}\text { High glycogen content } \\
\text { (grading } \geq 2 \text { ) }\end{array}$ & $6 / 14$ & $9 / 14$ & $8 / 12$ & $9 / 10$ & 0.16 & 0.19 & 0.15 & 0.15 \\
\hline
\end{tabular}

aMeans were compared using the Student's $t$-test

Dichotomous variables were compared using the Fisher's exact test

Table 2 Patients (recipients) characteristics before receiving IP or non-IP livers

\begin{tabular}{|c|c|c|c|c|c|c|c|c|}
\hline \multirow[b]{2}{*}{ Variable } & \multicolumn{2}{|c|}{ Non-steatotic allografts } & \multicolumn{2}{|c|}{ Steatosic allografts } & \multirow[b]{2}{*}{$\begin{array}{l}\text { P-value } \\
\text { I versus } \text { II }^{\mathrm{a}}\end{array}$} & \multirow[b]{2}{*}{$\begin{array}{l}\text { P-value } \\
\text { III versus IV }\end{array}$} & \multirow[b]{2}{*}{$\begin{array}{c}\text { P-value } \\
\text { I versus } \text { III }^{\mathrm{a}}\end{array}$} & \multirow[b]{2}{*}{$\begin{array}{l}\text { P-value } \\
\text { II versus IV }\end{array}$} \\
\hline & $\begin{array}{l}\text { IP }(n=14) \\
\text { group I }\end{array}$ & $\begin{array}{c}\text { Non-IP }(n=14) \\
\text { group II }\end{array}$ & $\begin{array}{l}\text { IP }(n=12) \\
\text { group III }\end{array}$ & $\begin{array}{l}\text { Non-IP }(n=10) \\
\text { group IV }\end{array}$ & & & & \\
\hline $\begin{array}{l}\text { Age of recipients (years) } \\
\text { Gender }(M / F)\end{array}$ & $\begin{array}{l}50 \pm 14 \\
8 / 6\end{array}$ & $\begin{array}{l}45 \pm 14 \\
9 / 5\end{array}$ & $\begin{array}{l}47 \pm 12 \\
10 / 2\end{array}$ & $\begin{array}{l}45 \pm 13 \\
9 / 1\end{array}$ & $\begin{array}{l}0.38 \\
0.28\end{array}$ & $\begin{array}{l}0.68 \\
0.43\end{array}$ & $\begin{array}{l}0.55 \\
0.13\end{array}$ & $\begin{array}{l}0.89 \\
0.15\end{array}$ \\
\hline \multicolumn{9}{|l|}{ Etiology } \\
\hline $\begin{array}{l}\text { Alcoholic cirrhosis } \\
\text { HBV cirrhosis } \\
\text { HCV cirrhosis } \\
\text { Others }\end{array}$ & $\begin{array}{l}2 / 14 \\
3 / 14 \\
4 / 14 \\
5 / 14\end{array}$ & $\begin{array}{l}2 / 14 \\
3 / 14 \\
4 / 14 \\
5 / 14\end{array}$ & $\begin{array}{l}4 / 12 \\
1 / 12 \\
3 / 12 \\
4 / 12\end{array}$ & $\begin{array}{l}3 / 10 \\
1 / 10 \\
3 / 10 \\
3 / 10\end{array}$ & $\begin{array}{l}0.40 \\
0.35 \\
0.32 \\
0.30\end{array}$ & $\begin{array}{l}0.35 \\
0.52 \\
0.77 \\
0.73\end{array}$ & $\begin{array}{l}0.20 \\
0.29 \\
0.32 \\
0.70\end{array}$ & $\begin{array}{l}0.26 \\
0.34 \\
0.64 \\
0.33\end{array}$ \\
\hline
\end{tabular}

aMeans were compared using the Student's $t$-test

Dichotomous variables were compared using the Fisher's exact test 
Table 3 Surgical data during liver transplantation in patients receiving a IP and non-IP allograft

\begin{tabular}{|c|c|c|c|c|c|c|c|c|}
\hline \multirow[b]{2}{*}{ Variable } & \multicolumn{2}{|c|}{ Non-steatotic allografts } & \multicolumn{2}{|c|}{ Steatosic allografts } & \multirow[b]{2}{*}{$\begin{array}{l}P \text {-value } \\
\text { I versus || }\end{array}$} & \multirow[b]{2}{*}{$\begin{array}{l}P \text {-value } \\
\text { III versus IV }\end{array}$} & \multirow[b]{2}{*}{$\begin{array}{c}P \text {-value } \\
\text { I versus } \text { III }^{\mathrm{a}}\end{array}$} & \multirow[b]{2}{*}{$\begin{array}{c}P \text {-value } \\
\text { II versus IV }\end{array}$} \\
\hline & $\begin{array}{l}\text { IP }(n=14) \\
\text { group I }\end{array}$ & $\begin{array}{c}\text { Non-IP }(n=14) \\
\text { group II }\end{array}$ & $\begin{array}{c}\text { IP }(n=12) \\
\text { group III }\end{array}$ & $\begin{array}{c}\text { Non-IP }(n=10) \\
\text { group IV }\end{array}$ & & & & \\
\hline $\begin{array}{l}\text { Allograft weight }(\mathrm{g}) \\
\text { Portal ischemic time (min) } \\
\text { Arterial ischemic time (min) } \\
\text { Blood units } \\
\text { Surgical complications } \\
\text { (vascular or biliary) }\end{array}$ & $\begin{array}{c}1333 \pm 192 \\
435 \pm 127 \\
36 \pm 25 \\
8.1 \pm 10.2 \\
3 / 14\end{array}$ & $\begin{array}{c}1533 \pm 403 \\
476 \pm 151 \\
35 \pm 24 \\
5.9 \pm 5.2 \\
2 / 14\end{array}$ & $\begin{array}{c}1622 \pm 494 \\
424 \pm 134 \\
50 \pm 22 \\
7.8 \pm 11.1 \\
3 / 12\end{array}$ & $\begin{array}{c}1540 \pm 314 \\
429 \pm 76 \\
40 \pm 15 \\
7.5 \pm 9.2 \\
3 / 10\end{array}$ & $\begin{array}{l}0.11 \\
0.44 \\
0.88 \\
0.46 \\
0.34\end{array}$ & $\begin{array}{l}0.67 \\
0.91 \\
0.26 \\
0.94 \\
0.35\end{array}$ & $\begin{array}{l}0.06 \\
0.83 \\
0.16 \\
0.94 \\
0.35\end{array}$ & $\begin{array}{l}0.96 \\
0.38 \\
0.56 \\
0.58 \\
0.27\end{array}$ \\
\hline
\end{tabular}

aMeans were compared using the Student's $t$-test

Dichotomous variables were compared using the Fisher's exact test

Table 4 Clinical data during liver transplantation in patients receiving a IP and non-IP allograft

\begin{tabular}{|c|c|c|c|c|c|c|c|c|}
\hline \multirow[b]{2}{*}{ Variable } & \multicolumn{2}{|c|}{ Non-steatotic allografts } & \multicolumn{2}{|c|}{ Steatosic allografts } & \multirow[b]{2}{*}{$\begin{array}{l}\text { P-value } \\
\text { I versus II III }\end{array}$} & \multirow[b]{2}{*}{$\begin{array}{l}\text { P-value } \\
\text { versus IV }{ }^{\mathrm{a}} \text { I }\end{array}$} & \multirow[b]{2}{*}{$\begin{array}{l}\text { P-value } \\
\text { | versus ||| }\end{array}$} & \multirow[b]{2}{*}{$\begin{array}{l}\text { P-value } \\
\text { versus IV }\end{array}$} \\
\hline & $\begin{array}{l}\text { IP }(n=14) \\
\text { group I }\end{array}$ & $\begin{array}{l}\text { Non-IP }(n=14) \\
\text { group II }\end{array}$ & $\begin{array}{l}\text { IP }(n=12) \\
\text { group III }\end{array}$ & $\begin{array}{l}\text { Non-IP }(n=10) \\
\text { group IV }\end{array}$ & & & & \\
\hline \multicolumn{9}{|l|}{ Hepatic function } \\
\hline AST at day 5 (IU/I) & $42 \pm 33$ & $79 \pm 57$ & $55 \pm 40$ & $139 \pm 164$ & 0.047 & 0.10 & 0.37 & 0.22 \\
\hline ALT at day 5 (IU/I) & $82 \pm 39$ & $247 \pm 194$ & $222 \pm 246$ & $423 \pm 409$ & 0.005 & 0.17 & 0.046 & 0.17 \\
\hline AST peak (IU/I) & $235 \pm 189$ & $458 \pm 308$ & $881 \pm 1323$ & $862 \pm 762$ & 0.029 & 0.96 & 0.08 & 0.09 \\
\hline ALT peak (IU/I) & $187 \pm 94$ & $577 \pm 361$ & $795 \pm 796$ & $728 \pm 724$ & 0.0006 & 0.84 & 0.009 & 0.51 \\
\hline $\mathrm{PT}(\%)$ at day 5 & $61 \pm 13$ & $67 \pm 10$ & $63 \pm 20$ & $68 \pm 9$ & 0.18 & 0.48 & 0.73 & 0.74 \\
\hline Bilirubin at day $7(\mu \mathrm{mol} / \mathrm{l})$ & $46 \pm 44$ & $38 \pm 21$ & $106 \pm 148$ & $78 \pm 45$ & 0.55 & 0.57 & 0.16 & 0.007 \\
\hline \multicolumn{9}{|l|}{ Hospitalization } \\
\hline Intensive care unit stay (days) & $12 \pm 7$ & $11 \pm 6$ & $15 \pm 10$ & $12 \pm 5$ & 0.67 & 0.42 & 0.47 & 0.59 \\
\hline Total stay in hospital (days) & $28 \pm 8$ & $29 \pm 13$ & $52 \pm 43$ & $33 \pm 9$ & 0.70 & 0.18 & 0.049 & 0.53 \\
\hline Retransplantation & $1 / 14$ & $1 / 14$ & $0 / 12$ & $0 / 10$ & - & - & 0.52 & 0.52 \\
\hline \multicolumn{9}{|l|}{ Rejection } \\
\hline Acute rejection & $2 / 14$ & $5 / 14$ & 2/12 & $6 / 10$ & 0.15 & 0.048 & 0.40 & 0.17 \\
\hline $\begin{array}{l}\text { Rejection activity index } \\
\text { (mean } \pm \text { S.D.) }\end{array}$ & $5 \pm 1.4$ & $5.2 \pm 1.3$ & $5 \pm 1.7$ & $4.7 \pm 0.9$ & 0.86 & 0.73 & 1.00 & 0.66 \\
\hline $\begin{array}{l}\text { Acute rejection delay } \\
\text { (median in month) }\end{array}$ & 0.5 & 1.25 & 0.5 & 2 & 0.84 & 0.92 & 0.99 & 0.99 \\
\hline Chronic rejection & $0 / 14$ & $2 / 14$ & $2 / 12$ & $7 / 10$ & 0.24 & 0.017 & 0.20 & 0.009 \\
\hline Ductopenia (mean \pm S.D. in \%) & - & $44.5 \pm 15.6$ & $49.7 \pm 23.1$ & $36.5 \pm 10.2$ & - & 0.15 & - & 0.22 \\
\hline $\begin{array}{l}\text { Chronic rejection delay } \\
\text { (median in month) }\end{array}$ & - & 42 & 9 & 36 & - & 0.09 & - & 1.00 \\
\hline $\begin{array}{l}\text { Follow-up (mean } \pm \text { S.D. } \\
\text { in months) }\end{array}$ & $53 \pm 18$ & $60 \pm 30$ & $47 \pm 27$ & $64 \pm 26$ & 0.44 & 0.16 & 0.51 & 0.76 \\
\hline
\end{tabular}

aMeans were compared using the Student's $t$-test

Dichotomous variables were compared using the Fisher exact test

Medians were compared with Kolmogorov-Smirnov test

(33 days versus 29 days) were observed between the 10 steatotic and the 14 non-steatotic grafts recipients (Table 4).

No differences in the incidence of acute rejection (AR 6/10 versus 5/14) nor in rejection activity index were observed (Table 4). However, a statistically significant increase in the incidence of chronic rejection (CR) was observed in recipients of steatotic grafts compared with recipients of non-steatotic grafts $(7 / 10$ versus $2 / 14 ; P<0.01)$, whereas no differences in severity of ductopenia was observed (Table 4).

Histological changes in livers following transplantation were analysed. Necrotic cells associated with polymorphonuclear infiltrate were observed in centrolobular areas, throughout the lobule and periportal spaces. Surgical necrosis was more frequently observed in patients receiving steatotic grafts compared with patients receiving non-steatotic grafts (10/10 versus 9/14 $P<0.05$; Figure 1, Table 5). However, no differences in necrotic index was observed between the two groups (Table 5). Apoptotic cell death was evaluated by activated caspase 3 immunostaining. Apoptotic cells were mostly detected in centrolobular areas in both steatotic and non-steatotic hepatocytes (Figure 2a). In particular, activated caspase 3 was more frequently detected in patients receiving steatotic grafts compared with non-steatotic grafts $(3 / 10$ versus $0 / 14 ; P=0.059$ ).

Effects of IP on clinical and histological outcomes of patients receiving steatotic allografts. IP did not significantly change transaminase peaks and day 5 levels in recipients of steatotic allografts. In particular, mean AST and ALT peaks were 881 and $795 \mathrm{IU} / \mathrm{l}$ in IP graft recipients compared with 862 and $728 \mathrm{IU} / \mathrm{I}$ in non-IP graft recipients. Mean AST and ALT day 5 levels were lower, but not significantly, in IP graft recipients compared with non-IP graft recipients (55 and $222 \mathrm{IU} / \mathrm{I}$ versus 139 and $423 \mathrm{IU} / \mathrm{I}$, 

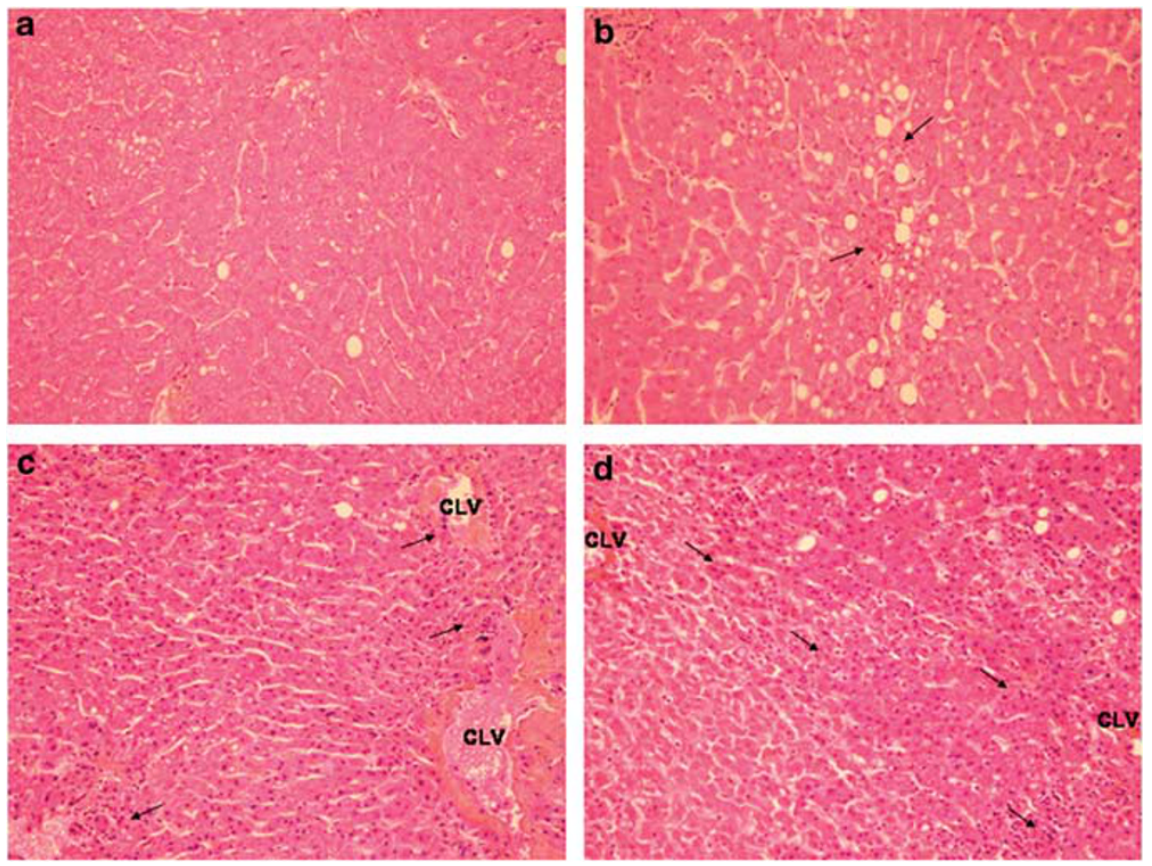

Figure 1 Representative images of different grades of necrosis. (a) Absence of necrosis $(\times 200)$. (b) Mild necrosis: few foci of polymorphonuclear cells (arrows) can be observed through the lobule surrounding few necrotic hepatocytes $(\times 200)$. (c) Moderate necrosis: some foci of polymorphonuclear cells can be observed around the section of the centrolobular vein $(\mathrm{CLV})$ associated to some necrotic hepatocytes $(\times 200)$. (d) Severe necrosis: large necro-inflammatory area with bridging between two centrolobular veins $(\mathrm{CLV} ; \times 200)$

Table 5 Histological and immunohistochemical and analysis on post-reperfusion livers

\begin{tabular}{|c|c|c|c|c|c|c|c|c|}
\hline \multirow[b]{2}{*}{ Variable } & \multicolumn{2}{|c|}{ Non-steatotic allografts } & \multicolumn{2}{|c|}{ Steatosic allografts } & \multirow[b]{2}{*}{$\begin{array}{c}P \text {-value } \\
\text { I versus }\left.\right|^{\mathrm{b}}\end{array}$} & \multirow[b]{2}{*}{$\begin{array}{l}P \text {-value } \\
\text { III versus IV }\end{array}$} & \multirow[b]{2}{*}{$\begin{array}{c}P \text {-value } \\
\text { I versus } \text { III }^{\mathrm{b}}\end{array}$} & \multirow[b]{2}{*}{$\begin{array}{c}\text { P-value } \\
\text { II versus IV }\end{array}$} \\
\hline & $\begin{array}{c}\text { IP }(n=14) \\
\text { group I }\end{array}$ & $\begin{array}{c}\text { Non-IP }(n=14) \\
\text { group II }\end{array}$ & $\begin{array}{l}\text { IP }(n=12) \\
\text { group III }\end{array}$ & $\begin{array}{c}\text { Non-IP }(n=10) \\
\text { group IV }\end{array}$ & & & & \\
\hline $\begin{array}{l}\text { Surgical necrosis (presence) } \\
\text { Absent } \\
\text { Mild } \\
\text { Moderate } \\
\text { Severe }\end{array}$ & $\begin{array}{l}9 / 14 \\
5 / 14 \\
7 / 14 \\
1 / 14 \\
1 / 14\end{array}$ & $\begin{array}{l}9 / 14 \\
5 / 14 \\
7 / 14 \\
1 / 14 \\
1 / 14\end{array}$ & $\begin{array}{l}8 / 12 \\
4 / 12 \\
5 / 12 \\
2 / 12 \\
1 / 12\end{array}$ & $\begin{array}{r}10 / 10 \\
0 / 10 \\
7 / 10 \\
3 / 10 \\
0 / 10\end{array}$ & $\begin{array}{l}0.30 \\
0.30 \\
0.29 \\
0.52 \\
0.52\end{array}$ & $\begin{array}{l}0.067 \\
0.067 \\
0.15 \\
0.30 \\
0.54\end{array}$ & $\begin{array}{l}0.32 \\
0.32 \\
0.28 \\
0.36 \\
0.52\end{array}$ & $\begin{array}{l}0.047 \\
0.047 \\
0.21 \\
0.16 \\
0.58\end{array}$ \\
\hline $\begin{array}{l}\text { Necrotic index } \\
\text { Activated caspase } 3 \\
\text { Beclin } 1 \\
\text { LC3 } \\
\text { Beclin 1+ LC3 }\end{array}$ & $\begin{array}{c}0.71 \pm 0.67 \\
0 / 12 \\
2 / 12 \\
2 / 12 \\
1 / 12\end{array}$ & $\begin{array}{c}0.67 \pm 0.61 \\
0 / 14 \\
0 / 14 \\
2 / 14 \\
0 / 14\end{array}$ & $\begin{array}{c}0.80 \pm 0.71 \\
1 / 12 \\
9 / 12 \\
9 / 12 \\
7 / 12\end{array}$ & $\begin{array}{c}0.97 \pm 0.32 \\
3 / 10 \\
2 / 10 \\
3 / 10 \\
2 / 10\end{array}$ & $\begin{array}{l}0.85 \\
\overline{0.20} \\
0.40 \\
0.46\end{array}$ & $\begin{array}{l}0.50 \\
0.20 \\
0.015 \\
0.046 \\
0.071\end{array}$ & $\begin{array}{l}0.75 \\
0.50 \\
0.006 \\
0.006 \\
0.014\end{array}$ & $\begin{array}{l}0.17 \\
0.059 \\
0.16 \\
0.26 \\
0.16\end{array}$ \\
\hline
\end{tabular}

a In all, 12 paraffin blocks were available for group I to allow further immunohistochemical analysis

${ }^{\mathrm{b}}$ Means were compared using the Student's $t$-test

Dichotomous variables were compared using the Fisher's exact test

respectively). Lower PT and higher serum bilirubin, although not significantly, were observed in IP grafts compared with non-IP grafts (Table 4). No significant differences in posttransplantation intensive care unit stays were observed between the two groups (15 days versus 12 days). Total hospitalization stay was longer, but not significantly different, for IP graft recipients compared with non-IP recipients (52 days versus 33 days; Table 4 ).

Interestingly, IP significantly decreased the incidence of both $A R$ and $C R$ in recipients of steatotic grafts compared with recipients of non-IP steatotic grafts (2/12 versus $6 / 10$ for $\mathrm{AR}$ and $2 / 12$ and $7 / 10$ for $\mathrm{CR} ; P<0.05$; Table 4). However, IP did not change the rejection activity index, nor severity of ductopenia in steatotic allografts (Table 4).
Histological examination showed that IP tended to decrease the incidence of surgical necrosis in steatotic grafts (8/12 versus $10 / 10 ; P=0.067$ ). However, no differences in necrotic index was observed between the two groups (Table 5). No difference in the detection of activated caspase 3 was observed in IP steatotic livers compared with non-IP steatotic livers (Table 5).

Effects of IP on clinical and histological outcomes of patients receiving non-steatotic allografts. IP significantly decreased both AST and ALT peak and day 5 levels in non-steatotic allografts recipients. In particular, mean AST and ALT peak were 235 and $187 \mathrm{IU} / \mathrm{I}$ in recipients of IP livers compared with 458 and 577 in recipients of non-IP livers 

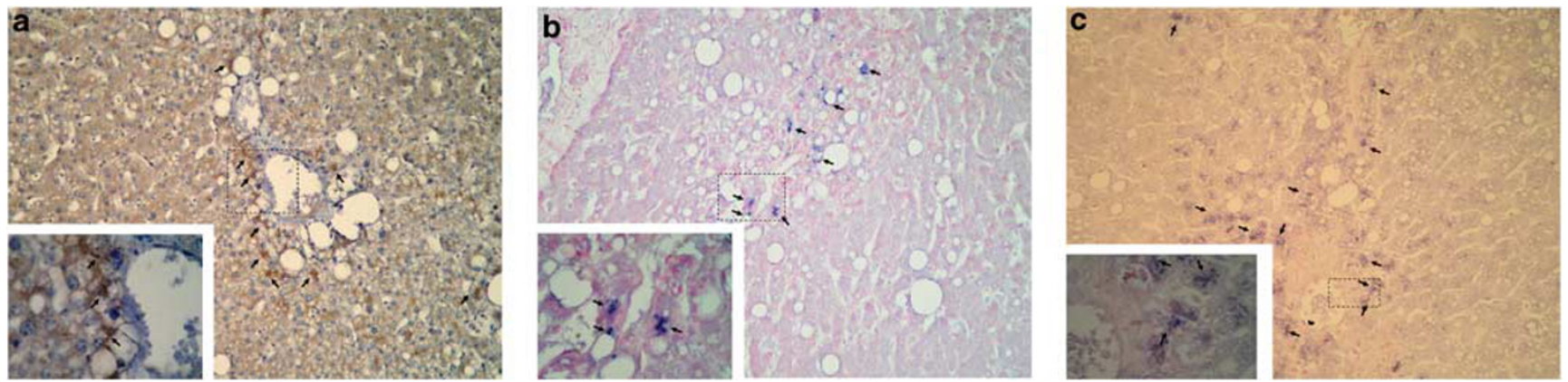

Figure 2 Assessment of activated caspase 3, beclin-1 and LC3 in steatotic preconditioned livers. (a) Activated caspase 3 expression in the hepatocytes of a centrolobular region (arrows; $\times 400$ ). Hepatocytes expressing activated caspase 3 circumscribed within the dashed lines are shown enlarged in the inset $(\times 1000)$. (b) Beclin-1 expression in the hepatocytes located in a centrolobular region and also in the lobule $(\times 400)$. Centrolobular hepatocytes expressing beclin-1 circumscribed within dashed lines are shown enlarged in the inset $(\times 1000)$. (c) LC3 expression in the hepatocytes located in a centrolobular region and also in the lobule $(\times 400)$. Centrolobular hepatocytes expressing LC3 circumscribed within dashed lines are shown enlarged in the inset $(\times 1000)$

$(P<0.05$ and $P<0.01$ for AST and ALT peaks, respectively). Mean AST and ALT day 5 levels were 42 and $82 \mathrm{IU} / \mathrm{l}$ in recipients of IP livers compared with 79 and $247 \mathrm{IU} / \mathrm{I}$ in recipients of non-IP livers $(P<0.05$ and $P<0.01$ for AST and ALT day 5 levels, respectively). Lower PT and higher serum bilirubin were observed, although not significantly, in IP grafts compared with non-IP grafts (Table 4). No significant difference in post-transplantation intensive care unit stays (12 days versus 11 days) or total hospitalization stays ( 28 days versus 29 days) was observed between the IP or non-IP non-steatotic graft recipients (Table 4).

No difference in the incidence of AR or CR was observed in these two groups (2/14 versus $5 / 14$ for $A R$ and $0 / 14$ versus $2 / 14$ for $C R$ ), as well as in rejection activity index or ductopenia severity (Table 4).

Histological examination did not show any difference in the incidence or severity of surgical necrosis neither in necrotic index (Table 5). No apoptotic cells were detected either in IP nor in non-IP biopsies (Table 5).

IP activates autophagy in steatotic allografts. As we previously showed that autophagy is activated by IP in steatotic and peliotic livers treated by chemotherapy, ${ }^{16}$ we investigated the presence of autophagy biomarkers in postreperfusion biopsies of this series to evaluate the potential role of autophagy in steatotic livers.

The presence of autophagy markers was assessed by immunohistochemical detection of beclin-1 and LC3, these two proteins being essential for the macroautophagic process and, respectively, representing an early and a late marker of autophagy. ${ }^{17}$ Hepatocytes showing positive staining for both proteins were found mainly in the centrolobular areas, although some positive hepatocytes were observed throughout the lobule (Figures $2 b$ and c). Beclin-1 and LC3 staining were rarely observed in post-reperfusion non-steatotic livers. In particular, only one IP non-steatotic liver was positive for both protein stains, whereas $7 / 12$ IP steatotic livers showed positive staining for both beclin-1 and LC3 $(P<0.05$; Table 5). Double-positive staining for beclin-1 and LC3 was more frequently observed in IP steatotic livers compared with nonIP steatotic livers, although the results did not reach statistical significance ( $7 / 12$ versus $2 / 10 ; P=0.07$; Table 5$)$. When we considered only immunohistochemical-positive biopsies, we observed a statistically significant increased number of beclin-1-positive cells in IP steatotic livers compared with non-IP steatotic livers (Figure 3). Interestingly, we observed an inverse correlation between the number of LC3-positive cells and the necrotic index in IP steatotic livers, whereas no correlation was observed in the other groups. No correlation between the number of beclin-1-positive cells and the necrotic index was observed (Figure 3).

\section{Discussion}

In this study, we showed that IP may be beneficial for both patients receiving either steatotic or non-steatotic allografts, although biological mechanisms mediating IP effects did differ. IP tended to reduce parenchyma necrosis and subsequent graft rejection incidence in recipients of steatotic grafts. The activation of autophagy could have an important role to ensure cell homeostasis, and limit necrosis and graft rejection in steatotic livers.

Ischemia was more deleterious in steatotic grafts compared with non-steatotic livers as shown by transaminase levels after transplantation and the presence of surgical necrosis in post-reperfusion biopsies of non-IP livers. Our results are in accordance with previous observations in human or experimental liver surgery. ${ }^{4,18}$ Chronic necrosis, generally associated with lower ATP levels ${ }^{19}$ and increased inflammatory response in the parenchyma, ${ }^{20}$ could explain that steatotic livers are less resistant to I/R injuries. ${ }^{4,18}$

The main parameter considered to assess $I / R$ injury was serum transaminases level. However, contrasting results were published. The discrepancies in the significance of transaminases values can be attributed to different sample timing after transplantation and to high interpatient variability, particularly in marginal grafts such as steatotic livers, as we can observe here, or grafts from donors $>60$ years of age. ${ }^{15}$ Indeed, we showed that IP significantly decreased transaminases levels in non-steatotic livers, whereas a nonsignificant decrease was observed in IP steatotic liver. Moreover, the groups of patients with improved transaminase levels did not benefit from shorter hospitalization stays, as also observed in other studies. ${ }^{21,22}$ Therefore, more accurate biological markers are needed to better assess $1 / R$ injuries and the subsequent effects of IP. 
a

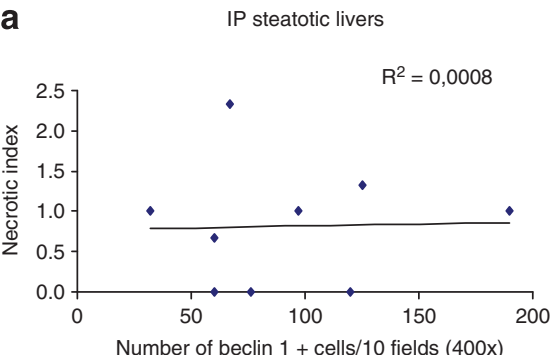

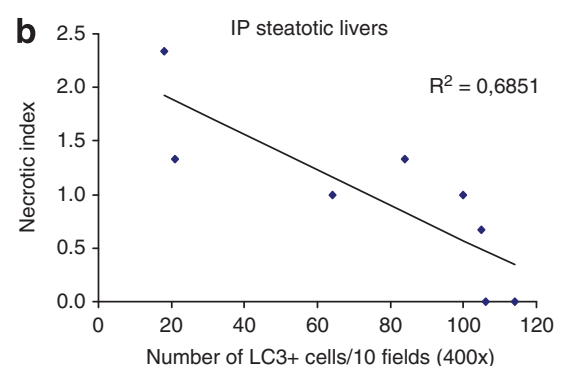

C Number of beclin1 or LC3 positive cells detected in 10 fields at 400x magnification in immunohistochemical positive biopsies

\begin{tabular}{lcccc}
\hline & $\begin{array}{c}\text { IP non steatotic livers } \\
(\mathrm{m} \pm \sigma)\end{array}$ & $\begin{array}{c}\text { Non- IP non steatotic } \\
\text { livers }(\mathrm{m} \pm \sigma)\end{array}$ & $\begin{array}{c}\text { IP steatotic livers } \\
(\mathrm{m} \pm \sigma)\end{array}$ & $\begin{array}{c}\text { Non- IP steatotic livers } \\
(\mathrm{m} \pm \sigma)\end{array}$ \\
\hline Beclin1 & $36 \pm 11$ & - & $82 \pm 31^{\#}$ & $25 \pm 1$ \\
LC3 & $35 \pm 21$ & $6 \pm 3$ & $71 \pm 40$ & $41 \pm 7$ \\
\hline \multicolumn{4}{r}{ \# Statistically significant $(\mathrm{p}<0.05)$ compared to non-IP steatotic livers using T-Student test }
\end{tabular}

Figure 3 Expression of autophagy markers in human liver biopsies and correlation with necrotic index. (a) Correlation between beclin-1 expression and necrotic index in IP steatotic livers. (b) Correlation between LC3 expression and necrotic index in IP steatotic livers. (c) Beclin-1 and LC3 expression in immunohistochemical-positive biopsies in all studied groups

Similarly, the decrease of apoptosis has been reported as a biological protective mechanism triggered by IP. ${ }^{23}$ It has been mostly assessed by TUNEL assay or caspase 3 or $\mathrm{Bcl}-2$ expression levels evaluation. However, results were not always conclusive. ${ }^{15,16,23}$ This can be because of the use of the TUNEL assay that can not discriminate between apoptosis or necrosis cell death, ${ }^{9}$ or to the comparison of groups of biopsies that included steatotic livers or livers from donors over the age of 60 . Indeed, steatotic livers have been reported to have higher levels of oxidative or nitrosative radicals with subsequent oxidized lipids and proteins, ${ }^{24}$ and consequently lower intracellular ATP levels, thus favoring necrotic cell death following $\mathrm{I} / \mathrm{R}$ injury. ${ }^{24,25}$ In our study, we observed that steatotic livers frequently exhibited necrosis although non-steatotic livers did not. Interestingly, IP tended to decrease the incidence of necrosis without changing apoptosis in IP steatotic livers. We can note, as in other studies, ${ }^{15,26}$ that apoptosis assessed by caspase 3 activation was not a major mechanism triggered by I/R. Few hepatocytes exhibited caspase 3 activation. We can hypothesize that other apoptotic pathways could be activated or that apoptosis was controlled. Recently, autophagy has been described to be activated in stress conditions to ensure cell survival by limiting necrosis or apoptosis in vivo. ${ }^{27}$ Autophagy is a catabolic pathway triggered following various stress conditions, such as starvation or transient hypoxia, and aimed to restore adequate intracellular ATP and aminoacids levels and to eliminate damaged organelles. ${ }^{28,29}$ It is reported that autophagy crosstalks with apoptotic and necrotic cell death pathways, ${ }^{17}$ and that activation of autophagy may favour cellular survival by decreasing reactive oxygen species production. ${ }^{30}$ In other cellular contexts, autophagy has been shown to retard cell death by suppressing ER stress. ${ }^{31}$ Actually, ER stress has been recently described to have a role in the pathogenesis of liver steatosis ${ }^{32,33}$ and ER stress inhibition has been shown to be protective under I/R in an experimental model of steatotic/ non-steatotic partial hepatectomy. ${ }^{34}$ Thus, we can speculate that in our context, activation of autophagy may be involved in
ER stress attenuation in steatotic livers, and that the modulation of autophagy and ER stress can have beneficial effects in liver pathologies. Accordingly, our group has described that IP can trigger autophagy to switch on/off necrosis and/or apoptosis in steatotic or peliotic livers from patients formerly treated by several courses of chemotherapy. ${ }^{16}$ In this study, the decreased trend of incidence of necrosis that we observed was associated with a significant increased expression of autophagy markers in steatotic livers. Thus, the induction of autophagy, especially in IP steatotic livers, was in favor of the restoration of sufficient energetic levels and aminoacids availability in injured hepatocytes to prolong their survival under I/R stress. It is noteworthy that high ATP levels have been correlated with better post-transplantation outcomes. ${ }^{35,36}$

Tissue necrosis and vascular injury caused by $\mathrm{l} / \mathrm{R}$ has been associated with an increased risk of acute and chronic graft rejection. ${ }^{37}$ Interestingly, in our study IP significantly decreased mild $A R$ and mild $C R$ incidences only in recipients of steatotic livers. A decrease in AR was previously observed in recipients of IP liver in other studies ${ }^{13-15}$ and in particular Franchello et al. showed that IP increased survival rates at 6 months in marginal grafts but not in non-marginal grafts (which had, however, a higher survival rate compared with marginal livers). The biological mechanism involved in the decrease graft rejection after IP remains to be elucidated. However, a decreased sensitivity in necrotic cell death that we and other authors observed ${ }^{15}$ and probably a decreased inflammatory response observed by another group ${ }^{13}$ may be involved. It has been hypothesized that perioperative allograft injury induced by I/R releases mediators, such as $\operatorname{TNF} \alpha, \operatorname{IL} 1 \alpha$, HMGB1, and cellular nucleotides, that enhance destructive adaptive immune responses driving vascular inflammation and production of IL1 $\beta$ within grafted organs. ${ }^{38}$ Interestingly, TNF $\alpha$ signaling, known as a mediator of inflammation in liver and adipose tissue, has been recently shown to be involved also in NAFLD pathogenesis. ${ }^{39,40}$ Thus, the induction of autophagy may promote cell survival by restoring adequate 
intracellular ATP levels and consequently decreasing the release of inflammation mediators by injured cells. In our clinical context, we cannot conclude whether autophagy has a pro-survival role or an ATP restoring function, but a better understanding of autophagy activation during IP may lead clinical improvements in post-transplantation outcomes of patients receiving steatotic grafts.

\section{Patients and Methods}

Study population and experimental design. Among the patients who underwent a liver transplantation in our institution from 2000: (1) in an elective situation, (2) with a whole deceased donor liver, (3) from a donor without cardiac arrest or severe hemodynamical instability before retrieval, we analyzed patients who received an IP steatotic graft $(n=12)$ and we compared them with age matched patients receiving non-IP steatotic liver grafts $(n=10)$, IP non-steatotic liver grafts $(n=14)$ or non-IP non-steatotic liver graft $(n=14)$. Only patients receiving a graft from a donor staying $<4$ days in an intensive care unit and not having an alcohol-induced accident were included in the study. The mean duration stay of donors in an intensive care unit was $1.9 \pm 1.1$ days. The protocol of preconditioning ( $10 \mathrm{~min}$ of portal triad clamping followed by $10 \mathrm{~min}$ of reperfusion followed by multiorgan recovery) is the same as used in the previous clinical studies performed at our institution. ${ }^{12,21}$ All post-reperfusion biopsies were taken at the same time before closure of the abdomen. The protocol was approved by our center's investigation and review board, and was always accepted by the teams recovering other organs. The pre-transplant characteristics of graft donors are shown in Table 1. I/R injury was evaluated as transaminase peak levels and transaminase levels 5 days after transplantation (day 5). A routine histological examination on post-reperfusion livers was performed to assess the degree of steatosis and surgical necrosis.

Each group was followed until July 2010 in order to evaluate the incidence and the grading of $A R$ and $C R$ of liver grafts after liver transplantation.

Histological evaluation. Samples were fixed in alcohol-formalin-acetic acid, embedded in paraffin and stained with standard haematoxylin eosin safran and picrosirius stain. Histological review was made by an experienced pathologist (MS) without knowledge of the state of IP of the graft or other clinical data. The review concerned post-reperfusion surgical biopsies. Histological features, including steatosis and 'surgical' necrosis, were assessed semi-quantitatively. Steatosis of macro and microvacuolar type was graded as mild (0-30\%), moderate (30-60\%) or severe $(60-100 \%)$. Severely steatotic livers are discarded and not used for transplantation. When mixed steatosis was observed, the overall degree was calculated adding the macro and microvacuolar degrees. 'Surgical' necrosis was defined as patchy necrosis associated with polymorphonuclear infiltrate and graded as mild (score $=1)$, moderate $($ score $=2$ ) and severe (score $=3$ ). To assess a necrotic index, the mean score between lobular, periportal and perivenous necrosis was calculated for each biopsy. The review also concerned liver biopsies performed in the recipient after liver transplantation, especially in order to assess the presence of $A R$ and $C R$, both graded according to the relevant Banff classifications. ${ }^{22} \mathrm{~A}$ rejection activity index was used to score liver allograft biopsies with $A R$, whereas severity of ductopenia was used to score liver allograft biopsies with $\mathrm{CR}$.

Immunohistological procedures. All but two liver samples were available for immunostaining. Immunohistology was performed on $4 \mu \mathrm{m}$ paraffin-embedded formalin-fixed tissue sections using activated anti-human rabbit caspase 3 (Cell Signaling, Beverly, MA, USA), anti-human mouse beclin-1 (an early and essential autophagic protein; BD Biosciences, Franklin Lake, NJ, USA) and anti-human rabbit anti LC3 (a late autophagic protein; MBL, Nagoya, Japan) antibodies. Antigen retrieval was obtained by heat at $97^{\circ} \mathrm{C}$ in a citrate buffer at $\mathrm{pH} 6$ and in Tris-citrate buffer for beclin- 1 and LC3 and at pH 9 with $0.5 \%$ saponine for activated caspase 3 . The revelation system was based on a three-step biotin-free immunophosphatase stain using 5-bromo-4-chloro-3-indolyl phosphate/nitroblue tetrazolium chromogene substrate (Dako, Glostrup, Denmark) followed by nuclear red counterstaining for beclin-1 and LC3 detection, whereas it was a one-step biotin free immunoperoxidase stain (ImmPress, Vector Laboratories, Burlingame, CA, USA) using 3,3-diamino-benzidine chromogene (Dako) substrate followed by Hemalun counterstaining for activated caspase 3 .
Statistical analysis. Results are expressed as mean and standard deviation. Mean results were compared in the different groups with the help of variance analysis. Student $t$-tests after normalization of variables were used to compare two means. For dichotomous variables, a Fisher exact test was used. Median was used to compare AR or CR delay. Median results were compared in the different groups with Kolmogorov-Smirnov tests.

\section{Conflict of Interest}

The authors declare no conflict of interest.

Acknowledgements. Davide Degli Esposti is a fellow of NRB-Vaincre le Cancer and Groupement Coopératif de Transplantation de l'lle de France.

1. Mahli H, Guicciardi ME, Gores GJ. Hepatocyte death: a clear and present danger. Physio Rev 2010; 90: 1165-1194.

2. Veteläinen R, van Vliet AK, van Gulik TM. Severe steatosis increases hepatocellular injury and impairs liver regeneration in a rat model of partial hepatectomy. Ann Surg 2007; 245: 44-50.

3. Peralta C, Roselló-Catafau J. The future of fatty livers. J Hepatol 2004; 41: 149-151.

4. Behrns KE, Tsiotos GG, DeSouza NF, Krishna MK, Ludwig J, Nagorney DM. Hepatic steatosis as a potential risk factor for major hepatic resection. J Gastrointest Surg 1998; 2: 292-298.

5. Canelo R, Braun F, Sattler B, Klinge B, Lorf T, Ramadori G et al. Is a fatty liver dangerous for transplantation? Transplant Proc 1999; 31: 414-415.

6. D'Alessandro AM, Kalayoglu M, Sollinger HW, Hoffmann RM, Reed A, Knechtle SJ et al. The predictive value of donor liver biopsies for the development of primary nonfunction after orthotopic liver transplantation. Transplantation 1991; 51: 157-163.

7. Murry $\mathrm{CE}$, Jennings $\mathrm{RB}$, Reimer KA. Preconditioning with ischemia preconditioning: a delay of lethal cell injury in ischemic myocardium. Circulation 1986; 74: 1124-1136.

8. Clavien PA, Selzner M, Rudiger HA, Graf R, Kadry Z, Rousson V et al. A prospective randomized study in 100 consecutive patients undergoing major liver resection with versus without ischemic preconditioning. Ann Surg 2003; 238: 843-850.

9. Jaeschke $\mathrm{H}$, Lemasters JJ. Apoptosis versus oncotic necrosis in hepatic ischemia/ reperfusion injury. Gastroenterology 2003; 125: 1246-1257.

10. Koti RS, Seifalian AM, Davidson BR. Protection of the liver by ischemic preconditioning: a review of mechanisms and clinical applications. Dig Surg 2003; 20: 383-396.

11. Barrier A, Olaya N, Chiappini F, Roser F, Scatton O, Artus C et al. Ischemic preconditioning modulates the expression of several genes, leading to the overproduction of IL-1Ra, iNOS, and Bcl-2 in a human model of liver ischemia-reperfusion. FASEB $J$ 2005; 19: 1617-1626.

12. Azoulay D, Del Gaudio M, Andreani $P$, Ichai $P$, Sebagh $M$, Adam R et al. Effects of 10 min of ischemic preconditioning on the cadaveric liver on the graft's preservation and function. Ann Surg 2005; 242: 133-139.

13. Jassem W, Fuggle SV, Cerundolo L, Heaton ND, Rela M. Ischemic preconditioning of cadaver donor livers protects allografts following transplantation. Transplantation 2006; 81: 169-174.

14. Koneru B, Shareef A, Dikdan G, Desai K, Klein KM, Peng B et al. The ischemic preconditioning paradox in deceased donor liver transplantation-evidence from a prospective randomized single blind clinical trial. Am J Transplant 2007; 7: 2788-2796.

15. Franchello A, Gilbo N, David E, Ricchiuti A, Romagnoli R, Cerutti $E$ et al. Ischemic preconditioning (IP) of the liver as a safe and protective technique against ischemia/ reperfusion injury (IRI). Am J Transplant 2009; 9: 1629-1639.

16. Domart MC, Degli Esposti D, Sebagh M, Olaya N, Harper F, Pierron G et al. Concurrent induction of necrosis, apoptosis, and autophagy in ischemic preconditioned human livers formerly treated by chemotherapy. J Hepatol 2009; 51: 881-889.

17. Maiuri MC, Zalckvar E, Kimchi A, Kroemer G. Self-eating and self-killing: crosstalk between autophagy and apoptosis. Nat Rev Mol Cell Biol 2007; 8: 741-752.

18. El-Badry AM, Moritz W, Contaldo C, Tian Y, Graf R, Clavien PA. Prevention of reperfusion injury and microcirculatory failure in macrosteatotic mouse liver by omega-3 fatty acids. Hepatology 2007; 45: 855-863.

19. Peralta C, Batrons R, Serafin A, Blazquez C, Guzman M, Prats M et al. Adenosin monophosphate-activated protein kinase mediates the protective effects of ischemic preconditioning on hepatic ischemia-reperfusion injury. Hepatology 2001; 34: 1164-1173.

20. VanSaun MN, Lee IK, Washington MK, Matrisian L, Gorden DL. High fat diet induced hepatic steatosis establishes a permissive microenvironment for colorectal metastases and promotes primary dysplasia in a murine model. Am J Pathol 2009; 175: 355-364.

21. Azoulay D, Lucidi V, Andreani $P$, Maggi U, Sebagh $M$, Ichai $P$ et al. Ischemic preconditioning for major liver resection under vascular exclusion of the liver preserving the caval flow: a randomized prospective study. J Am Coll Surg 2006; 202: 203-211.

22. Banff Working Group, Demetris AJ, Adeyi O, Bellamy CO, Clouston A, Charlotte F et al. Liver biopsy interpretation for causes of late liver allograft dysfunction. Hepatology 2006; 44: 489-501. 
23. Arkadopoulos N, Kostopanagiotou G, Theodoraki K, Farantos C, Theodosopoulos T, Stafyla $\mathrm{V}$ et al. Ischemic preconditioning confers antiapoptotic protection during major hepatectomies performed under combined inflow and outflow exclusion of the liver. A randomized clinical trial. World J Surg 2009; 33: 1909-1915.

24. Vendemiale G, Grattagliano I, Caraceni P, Caraccio G, Domenicali M, Dall'Agata M et al. Mitochondrial oxidative injury and energy metabolism alteration in rat fatty liver: effect of the nutritional status. Hepatology 2001; 33: 808-815.

25. Caraceni P, Bianchi C, Domenicali M, Maria Pertosa A, Maiolini E, Parenti Castelli G et al. Impairement of mitochondrial oxidative phosphorylation in rat fatty liver exposed to preservation-reperfusion injury. $J$ Hepatol 2004; 41: 82-88.

26. Arab HA, Sasani F, Rafiee MH, Fatemi A, Javaheri A. Histological and biochemical alterations in early-stage lobar ischemia-reperfusion in rat liver. World $J$ Gastroenterol 2009; 15: 1951-1957.

27. Minor T, Stegemann J, Hirner A, Koetting M. Impaired autophagic clearance after cold preservation of fatty livers correlates with tissue necrosis upon reperfusion and is reversed by hypothermic reconditioning. Liver Transplant 2009; 15: 798-805.

28. Huang J, Klionsky DJ. Autophagy and human disease. Cell Cycle 2007; 6: 1837-1849.

29. Scherz-Shouval R, Shvets E, Fass E, Shorer H, Gil L, Elazar Z. Reactive oxygen species are essential for autophagy and specifically regulate the activity of Atg4. EMBO J 2007; 26 $1749-1760$.

30. Rouschop KM, Ramaekers CH, Schaaf MB, Keulers TG, Savelkouls KG, Lambin P et al. Autophagy is required during cycling hypoxia to lower production of reactive oxygen species. Radiother Oncol 2009; 92: 411-416.

31. Choi $\mathrm{CH}$, Jung YK, Oh SH. Autophagy induction by capsaicin in malignant human breast cells is modulated by p38 and extracellular signal-regulated mitogen-activated protein kinases and retards cell death by suppressing endoplasmic reticulum stress-mediated apoptosis. Mol Pharmacol 2010; 78: 114-125.

32. Lee $\mathrm{AH}$, Glimcher LH. Intersection of the unfolded protein response and hepatic lipid metabolism. Cell Mol Life Sci 2009; 66: 2835-2850.
33. Ji C. Dissection of endoplasmic reticulum stress signaling in alcoholic and non-alcoholic liver injury. J Gastroenterol Hepatol 2008; 23 (Suppl1): S16-S24.

34. Mosbah IB, Alfany-Fernàndez I, Martel C, Zaouali MA, Bintanel-Morcillo M, Rimola A et al. Endoplasmic reticulum stress inhibition protects steatotic and non-steatotic livers in partial hepatectomy under ischemia-reperfusion. Cell Death and Dis 2010; 1 (e52): $1-12$

35. Lanir A, Jenkins RL, Caldwell C, Lee RG, Khettry U, Clouse ME. Hepatic transplantation survival: correlation with adenine nucleotide level in donor liver. Hepatology 1988; 8: 471-475.

36. Marni A, Ferrero ME, Gaja G. Metabolic function of grafted liver in rats. Transplantation 1988; 46: 830-835.

37. Halloran PF, Homik J, Goes N, Lui SL, Urmson J, Ramassar V et al. The 'injury response': a concept linking nonspecific injury, acute rejection, and long-term transplant outcomes. Transplant Proc 1997; 29: 79-81.

38. Rao DA, Pober JS. Endothelial injury, alarmins, and allograft rejection. Crit Rev Immunol 2008; 28: 229-248.

39. Fiorentino L, Vivanti A, Cavalera M, Marzano V, Ronci M, Fabrizi M et al. Increased tumor necrosis factor $\alpha$-converting enzyme activyty induces insulin resistance and hepatosteatosis in mice. Hepatology 2010; 51: 103-110.

40. Menghini R, Menini S, Amoruso R, Fiorentino L, Casagrande V, Marzano V et al. Tissue inhibitor of metalloproteinase 3 deficiency causes hepatic steatosis and adipose tissue inflammation in mice. Gastroenterology 2009; 136: 663-672.

\section{(c)}

SOMERIEHIS RES

Cell Death and Disease is an open-access journal published by Nature Publishing Group. This work is licensed under the Creative Commons Attribution-Noncommercial-No Derivative Works 3.0 Unported License. To view a copy of this license, visit http://creativecommons.org/licenses/by-nc-nd/3.0/ 